\title{
O Setor Externo da Economia e as Pedras no Caminho
}

RICARDO MOURA

Economista, Assessor do Ministro do Planejamento e Coordenação Geral

INTRODUÇÃO

Para colocar o assunto, é de se ter presente que nos países de baixa renda per capita, como o Brasil, a formação de capital - fator dinâmico de qualquer sistema econômico - vê-se sèriamente obstaculada, porque sendo baixa a renda é também baixa a capacidade de poupança, elemento fecundador dos investimentos. Em alguns núcleos populacionais, essa capacidade de poupança nem mesmo existe, tal o grau de miserabilidade em que ainda se encontram. Compreende-se que para êsse contingente humano, à medida que o progresso avança e que se opera melhor distribuição da renda, haverá, antes, alta propensão a consumir do que a poupar.

Mas os óbices para elevar a taxa de investimento não são apenas êsses - baixa capacidade de poupança e alta propensão a consumir. Além disso, nos paises subdesenvolvidos costuma também ser muito alta a relação capital-produto, que se traduz num baixo coeficiente de produtividade.

Ademais, no caso brasileiro, como todos sabem, é elevadíssimo o coeficiente de expansão demográfica. E aqui surge nôvo óbice ao nosso processo de desenvolvimento, de vez que o crescimento do Produto Nacional, à simples taxa de aumento da população, representa mera estagnação econômica. Isto significa que até para ficar parado o Brasil tem que correr, como alguém que estivesse tentando subir uma escada rolante pelo lado da descida. 
O que importa, pois, se se pretende vencer a estagnação, é alcançar uma taxa de crescimento que supere, em boa margem, a de expansão demográfica, em tudo quanto possa ser compativel com o sacrifício exigido dentro dos padrões das franquias democráticas.

Dado, porém, que o investimento é o fator dinâmico do processo de desenvolvimento, convém não perder de vista que sua composição depende, em larga medida, da importação de bens de capital, e que a dinamização do estoque de capital existente também depende da importação de produtos intermediários (insumos ou inputs na linguagem dos economistas), além de matérias-primas pròpriamente ditas, sem falar na importação de tecnologia, mesmo materializada em bens tangíveis ou equipamentos, que assume um dos aspectos mais importantes na atual quadra do desenvolvimento nacional.

E, uma vez que a capacidade para importar é a resultante das exportações, do movimento de capitais e das relações de intercâmbio, especial atenção deve ser dada a todos seus componentes, a fim de que não se comprometa a taxa de expansão da economia brasileira.

A propósito, convém também não perder de vista que o superavit em conta corrente do Balanço de Pagamento é intrinsecamente igual ao excedente do Produto sôbre os gastos nacionais e vice-versa.

Entretanto, para alguns, a doutrina mercantilista, que considerava o superavit nas contas internacionais como o único meio de aumentar a riqueza de uma Nação, parece não estar, ainda, completamente sepultada. Recalcitrantes há que não se dão conta de que um deficit em contas correntes do Balanço de Pagamentos, quando superposto por inversões líquidas de capital, faz com que, não obstante êsse mesmo deficit, o País se fortaleça econômicamente. Recìprocamente, um superavit em contas correntes seguido de resultado negativo no movimento de capitais é a pior hipótese.

Por isso, como determinante de maior ou menor aumento da riqueza nacional, o que se tem de considerar é a soma algébrica do Balanço de Pagamentos em contas correntes mais as inversões líquidas de capital.

Em tese, quando um país aspira a melhorar sua balança comercial e contribuir, portanto, para fortalecer, também, seu 
Balanço de Pagamentos, depara-se frente a dois caminhos: diminuir as importações ou aumentar as exportações. Este último recurso (opção brasileira atual) é, sem dúvida, o preferível, de vez que é muito difícil, e em certos casos até impossível, reduzir as importações sem diminuir ao mesmo tempo as atividades econômicas. Nunca esquecer, porém, que é necessário dar racionalidade às importações, e não importar por importar, como, também, não faz sentido exportar por exportar. Exportar não é um fim em si mesmo, antes é um meio para pagar importações de que o país carece, inclusive para atender 0 item de invisiveis e encargos de capitais.

O Professor Roberto Campos costuma classificar, e com razão, nosso Balanço de Pagamentos como do tipo perverso. Se está muito bom, pode ser ruim, e quando está ruim, é porque está ruim mesmo.

$\mathrm{Na}$ verdade, seguidos superavits nas contas internacionais podem agudizar o processo inflacionário, por fôrça de injeções de papel-moeda no meio circulante, em decorrência do excesso de compras sôbre as vendas de câmbio. De outra parte, quando nas mesmas transações econômicas com o Exterior, o País cai na incômoda contingência de atrasados comerciais, desponta também outro fato gerador de inflação, por isso que os fornecedores lançam mão do over-price nas vendas de seus produtos, ou cobram juros mais altos para as importações financiadas, com vistas a cobrir o risco já evidente da provável inadimplência dos pagamentos contratuais. E mais. Quando o País se empenha em luta para buscar o equilíbrio no Balanço de Pagamento e restringe, então, suas importações, pode estar palmilhando o pior caminho, ou seja, o da "estagninflação", que, no dizer do próprio Professor Roberto Campos, criador do neologismo, é "o sinistro conúbio entre a alta geral de preços e a estagnação econômica".

O periodo da Segunda Guerra Mundial é exemplo conspícuo de como nossas contas internacionais, por terem sido muito boas, financeiramente, nos causaram ingentes sacrificios, e, por isso, se olhadas pela ótica econômica, elas nos foram perversamente más.

Com efeito, dados disponíveis na época demonstravam que em 1942/43 a percentagem de influência dos saldos do Balanço de Pagamentos sôbre a inflação era de $58 \% .{ }^{1}$ Quer

1. Humberto Bastos - "Vivemos uma Revolução" - in Revista do ex-Conselho Nacional de Economia - no 2, de 1963. 
dizer, o esfôrço produtivo nacional para suprir nossos aliados de bens e serviços, sem a contrapartida de maiores importações, levou-nos a financiar a compra de câmbio pelo processo de emissões primárias de papel-moeda, elevando, conseqüentemente, a taxa inflacionária.

Basta dizer que a nossa balança comercial (exportação FOB versus importação CIF), no periodo de 1941/46, propiciou um saldo de 18 bilhões de cruzeiros da época (cêrca de US\$. . 900 milhões).

Com o término do conflito, e mais ou menos regularizado o sistema internacional de transporte marítimo, explodiu a procura reprimida pelas importações, então coartadas, principalmente para reaparelhamento de nossos parques industriais e de transportes, em que nosso esfôrço de guerra deixou marcas palpáveis de desinvestimentos ou autofagia econômica.

Havia também um aspecto puramente financeiro nessas necessidades de importação. Era o de que deveríamos comprar tanto quanto possível no Exterior para diminuir o impacto das pressões inflacionárias geradas pela acumulação forçada de divisas. Em outras palavras, a crença da época era vender o máximo de divisas para reforçar, em cruzeiros, os cofres do Tesouro.

$\mathrm{Na}$ verdade, nossas importações deram um salto impressionante, passando de 9 bilhões de cruzeiros da época, em 1945, para 23, em 1947, mantendo-se na casa dos 21 até 1955.

Todavia, muita gente se esquece (e é de bom aviso apontar êste fato numa revista ligada à técnica administrativa) que a ânsia de repor numerário em cruzeiros à caixa do Tesouro nos levou também a permitir inusitada fuga de capitais, fato que se operou em pura perda para a economia nacional.

Com efeito, no período de 14 anos (1939/52), o resultado do movimento de capitais e serviços correlatos apresentou deficits continuados e vultosos. Os saldos líquidos de exportação atingiram, nesse periodo, o total de $\mathrm{Cr} \$ 6.136$ milhões antigos, em contraste com o movimento negativo de capitais e rendas no montante de $\mathrm{Cr} \$ 17.640$ milhões. Em outras palavras, além de absorver o saldo apurado na balança comercial, os capitais consumiram o superavit obtido em outras verbas.

No período de 1941 a 1946, em que as contingências da guerra forçaram a acumulação de vultosas disponibilidades no exterior (o que valeu, aliás, por um financiamento feito pelo 
Brasil ao desenvolvimento do programa bélico dos nossos aliados), verificou-se verdadeira descapitalização financeira de investimentos estrangeiros, cuja saída líquida, rendas inclusive, absorveu $44 \%$ dos saldos da balança comercial.

\section{Período 1941/1946 - Saldos}

(em milhões de cruzeiros antigos)

a) Balança Comercial (exportação FOB, importação CIF)

b) Donativos e Movimento de Capitais Privados - 563

c) Financiamentos Oficiais Especiais ....... - 1.554

d) Resultado do Movimento de Capitais $(b+c)$. -2.117

e) Rendas de Investimentos .............. - 5.887

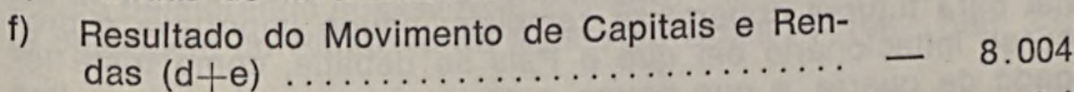

No após-guerra e até 1952 tivemos um deficit comercial de 12.591 milhões de cruzeiros antigos; no mesmo período, os capitais estrangeiros e suas rendas ainda nos oneraram o Balanço de Pagamentos com o saldo negativo de 8.514 milhões de cruzeiros antigos.

\section{Período 1947/1952 - Saldos}

(em milhões de cruzeiros antigos)

a) Balança Comercial (exportação FOB, importação $\mathrm{CiF}$ ) .......................... 12.591

b) Donativos e Movimento de Capitais Privados + 2.302

c) Financiamentos Oficiais Especiais ........ - 2.118

d) Resultado do Movimento de Capitais $(b+c)$. 184

e) Rendas de Investimentos ............. - 8.698

f) Resultado do Movimento de Capitais e Ren- $\quad 8.514$ das $^{2}(\mathrm{~d}+\mathrm{e})$

Dissemos alhures ser de bom aviso apontar os fatos acima numa revista ligada precipuamente à técnica administra-

2. FONTES. Saldos da Balança Comercial: Estatística Econômica e Financeira do Ministério da Fazenda.

DEMAIS DADOS: De 1939 a 1946, extraídos do trabalho "Inflation in Brazil - 1940/50", de autoria do Sr. E. M. Berstein, Diretor do Departamento de Pesquisas do F.M.I.; de 1947 a 1951: F.M.I., Balance of Payments Yearbook, Vol. IV; 1952 - Levantamento preliminar feito pela antiga Assessoria Técnica da Superintendência da Moeda e do Crédito. 
tiva. E por que? Porque, ainda não desenvolvida e disseminada entre nós a ciência administrativa, incorremos, quanto à fuga de capitais, em êrro palmar de direito administrativo, extravasando o círculo em que se deveria circunscrever o poder regulamentar.

É que, em 1946, com o advento do Decreto-lei no 9.025, de 27 de fevereiro, criou-se entre nós um instituto legal para disciplinar as remessas de rendas e repatriamento dos capitais estrangeiros investidos no País.

Entretanto, o regulamento do citado Decreto-lei no 9.025, indo muito além do que Ihe era permitido, tornou nulo o instituto do retôrno ou transferência de capital, pois admitiu, sem limitações, que o lucro excedente desta ou daquela percentagem, reinvestido ou não, pudesse aglutinar-se ao capital original para futuras coberturas cambiais; pouco importava o processo inflacionário em que o País se debatia, como triste legado de guerra, e que pouco a pouco ia minando a taxa fixa de câmbio, tida como a de equilibrio, com base na paridade de $\operatorname{Cr} \$ 18,50$ antigos por um dólar.

Isto, porém, ainda parecia pouco, e, a 26 de agôsto de 1946 (apenas seis meses após a promulgação do Decreto-lei n? 9.025), as autoridades monetárias deliberavam tornar inteiramente livre o movimento de capitais, abolindo (e também aqui com exorbitância do poder regulamentar) quaisquer limitações às remessas de rendas ou de retôrno dos investimentos realizados no País.

É curioso observar que, "considerando os prejudiciais efeitos de ordem econômica e financeira das aquisições imoderadas de artigos de essencialidade reduzida", em março de 1947 era restabelecido o regime de prévio licenciamento das importações, continuando, porém, a liberdade do movimento de capitais.

Note-se que, apesar da liberação desabrida das importações e fuga de capitais, manteve-se, talvez por um ranço mercantilista, a compra de ouro às minas nacionais, num contrasenso insofismável da política monetária então seguida. De um lado, procurava-se reforçar as arcas do. Tesouro em cruzeiros, mediante vendas de câmbio, e, de outro, eram retirados cruzeiros dos cofres públicos para compra de ouro. Ouro que, saindo do fundo da terra, ia, depois dos gastos em cruzeiro para sua aquisição, ser guardado a sete chaves no fundo do Fort Knox. 
Mas até o tabu do ouro foi quebrado. Todos sabem que, sempre a duras penas e, de certo modo, de maneira vexatória, íamos conseguindo financiamentos compensatórios e/ou reescalonamento de dividas para cobrir os deficits do nosso Balanço de Pagamentos. Tais empréstimos eram sempre feitos a prazo curto ou médio, sem um mínimo de correlação com as nossas possibilidades de pagamento, obrigando-nos a renegociações constantes, embaraçosas e, sobretudo, impertinentes, por serem desnecessárias, se fôsse outra a compreensão internacional. Haja vista que, em 1953, quando nossos atrasados comerciais chegaram ao ápice, negociamos um empréstimo do tipo stand-by com o Eximbank, no valor de US\$300 milhões, mas cujo prazo de resgate, sabidamente impossível de concretização, foi, de início, fixado para apenas 2 anos. E, para obtenção dêsses empréstimos compensatórios fomos pouco a pouco penhorando nossas reservas-ouro, como se vê da seguinte passagem do Relatório do Banco do Brasil - 1962, pág. 33:

"Em 31-12-62, do ouro de propriedade do Tesouro Nacional depositado no exterior (243.956.061,904 gramas), achavam-se no Federal Reserve Bank, de Nova York, 243.955.989,338 gramas, das quais 181.816.059,509 gramas (US\$ 204.593.245,64) garantem o empréstimo de US\$ 200 milhões obtidos em 1954 junto a um consórcio de bancos norte-americanos; 44.939.955,726 gramas (US $\$ 50.007 .215,00$ ) respondem por operação ajustada em 27-12-62, no total de US\$ 50 milhões, não utilizados até final do exercício; o restante, ou seja, 17.700.046,669 gramas (US\$19.917.437,47), incluídas 72,566 gramas depositadas no Fundo Monetário Internacional, representa reserva livremente utilizável."

Com o agravamento da crise cambial em 1953 e depois de enfrentar a perversidade de um Balanço de Pagamentos bom demais, passou o Brasil a experimentar a maldade intrínseca da outra face da medalha, traduzida na agressividade do que é ruim em si mesmo, isto é, débitos continuados e crescentes em suas contas internacionais, até aos famigerados atrasados comerciais que, em linguagem menos cabalística, traduzem-se por dividas contraídas, vencidas e não solvidas ou moratória unilateral, se quiserem.

Já então não importava o nosso sacrifício dos anos de guerra. Embalde, Roberto Simonsen clamou por um Plano Marshall mirim para a América Latina, na Conferência de Bogotá (1948). 
Todavia, mais parecendo vencido do que vencedor, o Brasil saíra da Guerra tendo que pagar dívida (Lend-Lease). E o fêz com humildade, a prestação, mas honradamente.

Enquando isso, sentindo que os dois pilares financeiros da Convenção de Bretton Woods (Fundo Monetário Internacional e Banco Mundial) eram impotentes para a realização do ideal grandioso ali sonhado, os Estados Unidos lançaram na Europa as benesses do Plano Marshall, assim tão bem descrito por André Philip:

“1) Son but est un investissement collectif, visant non pas à effectuer des opérations individuelles rentables, mais à maintenir le niveau de vie et la liberté politique en Europe, c'est-à-dire les choses sans prix sur le marché. L'E.C.A. est à se sujet la première expérience de crédit économique international dirigé. Elle établit des programmes, veille à l'emploi correct des fonds, fixe les règles de financement des échanges et productions appropriés à l'intérêt général.

2) L'investissement est gratuit; une minorité a été accordée sous forme de prêts à très faible taux d'intérêt, mais plus de $90 \%$ des fonds ont pris la forme de dons.

3) Enfin, au lieu d'examiner chaque investissement de façon individuelle, chaque pays a calculé ses besoins d'ensemble que l'O.E.C.E. s'est efforcé de présenter dans un programme général; à une demande collective a répondu une offre collective. Au lieu de calculs particuliers de rentabilité isolée, on a usé d'une méthode générale, établissant un ordre d'urgence objective; au lieu de ratifier des indications préalables de la demande, le Plan Marshall a établi des structures neuves, dont devait dépendre le rétablissement l'une demande nouvelle.

En fait, nous sommes là devant la première expérience d'un investissement international à caractère collectif; on pourrait dire, si ce mot ne faisait pas peur à nos amis américains, une première expèrience d'investissement international à caractère socialiste." 3

Muito menos ambiciosamente do que um Plano Marshall, ainda que mirim, o Brasil, nos trabalhos da Missão Abbink (Co-

3. André Philip - L'Europe unie et sa place dans l'économie internationale - Presses Universitaires de France - 1953. 
missão Mista Brasil-Estados Unidos para Desenvolvimento Econômico 1949/50), desejava apenas que a cooperação econômica levada a efeito com tanto êxito durante os anos difíceis da guerra continuasse também no após-guerra.

A venda de nossos materiais estratégicos (mica, cristal de rocha, tungstênio, areia monazítica, berilo, cério, borracha, sêda natural, piretro, rotenona, babaçu, mamona, manganês, minério de ferro etc) a preços tabelados em moeda estrangeira durante a guerra, por fôrça dos chamados Acôrdos de Washington, impediu a valorização de nossa moeda, quando em bases comerciais comuns, isto é, sem o espírito de cooperação, outra evidentemente teria sido a atitude do Brasil, cobrando, como seria natural, mais caro por seus produtos. Åquela época, a simples valorização do cruzeiro, plenamente justificável, seria o passo certo em têrmos econômico-financeiros.

E, quando no imediato após-guerra tanta celeuma se levantou a respeito dos atrasados comerciais com os Estados Unidos, deve-se ter presente que no mesmo impasse se debateu a Inglaterra com o Brasil. Tivemos nada menos do que 68 milhões de esterlinos congelados. O Economista Humberto Bastos, membro do ex-Conselho Nacional de Economia, assim descreve o episódio: ${ }^{4}$

"Em 1947, quando o Brasil, por intermédio do Sr. Vieira Machado e do Embaixador Moniz de Aragão, desejou liberar pelo menos parte dêsses atrasados comerciais acumulados e que seriam de grande utilidade, principalmente no combate à pressão inflacionária entre nós, o Sr. David Waley, subsecretário do Erário, enviou um ofício dizendo que o Chanceler do Erário não liberaria mais de 6 milhões, durante um prazo de quatro anos. Acrescentava ainda nesse documento: "Seria um gesto muito bem recebido pelo Govêrno Inglês se o Govêrno Brasileiro lhe propusesse o cancelamento de uma parte dos seus saldos em esterlinos, como reconhecimento do fato de terem caído os sacrifícios financeiros da guerra muito mais pesadamente sôbre o Reino Unido do que sôbre outros aliados."

O Brasil, na época, desejava apenas o pagamento de $29 \%$ dos atrasados resultantes de exportação para a

4. Humberto Bastos - Obra citada. 
Inglaterra, cujos esterlinos foram comprados com emissões de papel-moeda para atender aos exportadores, fato que representou um forte fator inflacionário.

Posteriormente, o Sr. Hugh Dalton, Chanceler do Erário, escreveu ao Embaixador Moniz de Aragão, reiterando: "Quero sugerir que a questão do cancelamento voluntário pelo Brasil de parte dos créditos congelados em esterlinos deveria ser ativamente considerada". A resposta do Embaixador Aragão foi franca: "Pelas razões que dou acima e tomando em consideração as enormes dificuldades que o povo brasileiro está também sofrendo, meu govêrno lamenta não poder ir ao encontro da sugestão apresentada". A essa decisão o Sr. Hugh Dalton retrucaria: "Não devo ocultar que a sua resposta constituiu um desapontamento para mim".

Depois de sucessivas negociações, que se prolongaram durante cêrca de quatro anos, os saldos brasileiros foram liberados em pequena parte relativa e o restante foi utilizado nas seguintes operações: pagamento à Brasil Railway Co. Ltd., compra de títulos da Dívida Externa, encampação da São Paulo Railway, "Great Western", The State of Bahia South Western Railway, adiantamento à Leopoldina Railway, encomenda de equipamentos ferroviários a serem fornecidos pela indústria britânica, compra dos prédios da Embaixada, Chancelaria e Consulado do Brasil em Londres, resgate do "coffee Loan" e de outros títulos."

E, sempre com negociações episódicas, em nossas relações econômicas internacionais, cansativas e difíceis, porque sem altanaria, que só o saudoso Presidente Kennedy soube colocar, quando do lançamento da "Aliança para o Progresso", infelizmente frustrada nos seus elevados objetivos, como o foi também a "Carta de Punta del Este", o Brasil, já em fins de 1962, no período pré-revolucionário de 31 de Março, ingressava, de nôvo, no incômodo regime de atrasados comerciais. Êstes se elevavam, em fins de 1962, a US\$ 128 milhões. Nesse mesmo ano, nossos compromissos a curto e médio prazos quase se parelhavam com os de longo prazo, na ordem de 1,7 bilhão de dólares. Ainda: enquanto as obrigações do primeiro grupo aumentavam de US\$ 271 milhões, entre 1961 e 1962, as do primeiro (compromissos a longo prazo) foram acrescidas de ape- 
nas US\$ 61 milhões. Em conseqüência, o agravamento geral da situação cambial do País, em 1962, fôra de US\$ 332 milhões.

\section{SITUAÇÃO CAMBIAL}

(Em milhões de dólares)

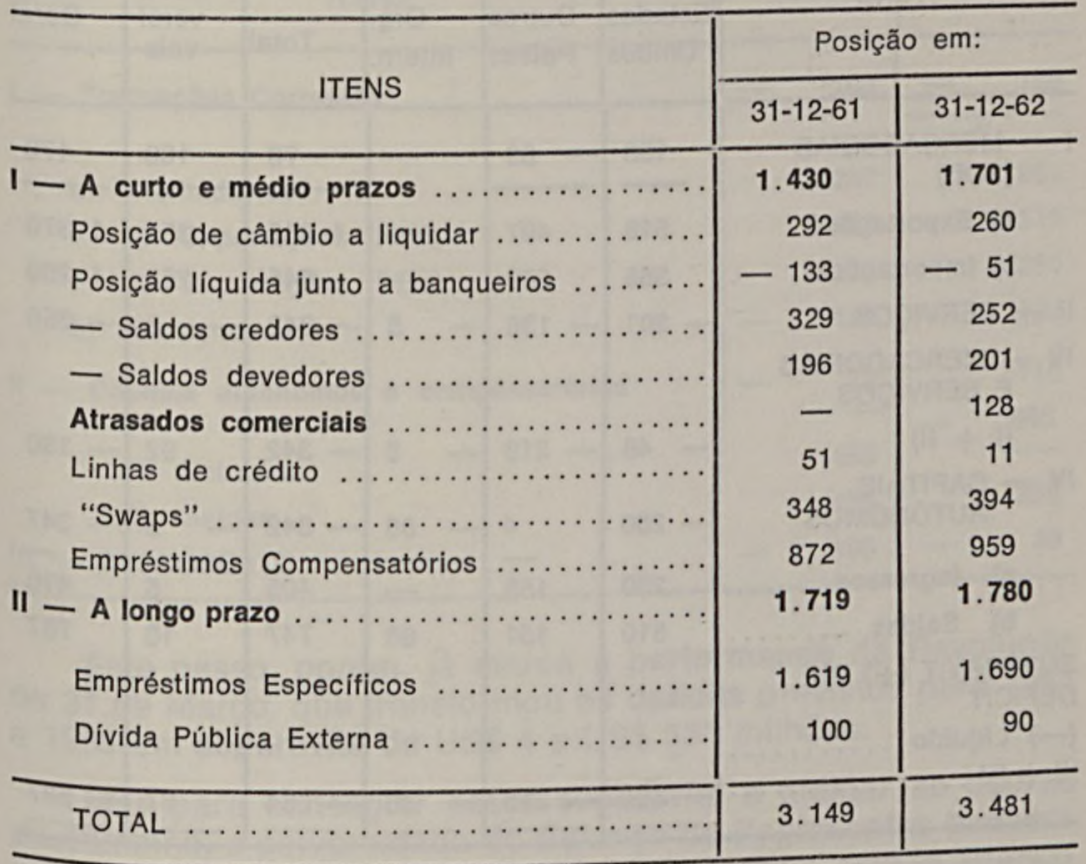

Fonte: Ex-SUMOC.

Tão graves então se desenhavam as relações econômicas do País com o Exterior que as projeções do Balanço de Pagamentos não escondiam a necessidade de se criarem "Descobertos" em nossa situação cambial. "Descobertos" ou deficits para os quais não se vislumbrava a maneira de financiá-los.

Segundo estimativas da SUMOC, em 1962, o deficit do Balanço de Pagamentos entre Transações Correntes e Movimento de Capitais Autônomos seria, naquele ano, de 527 milhões de dólares. Para a cobertura dêsse defícit, tinha-se aprazado apenas um minguado financiamento compensatório de apenas 63 milhões de dólares, de sorte que o Descoberto seria de 464 milhões. 
PROJEÇÃO EM 1962 DO BALANÇO DE PAGAMENTOS PARA 1963

(em milhões de dólares)

\begin{tabular}{|c|c|c|c|c|c|c|}
\hline \multirow[b]{2}{*}{ ITENS } & \multicolumn{4}{|c|}{ MOEDAS CONVERSIVEIS } & \multirow{2}{*}{$\begin{array}{c}\text { Moedas } \\
\text { Incon- } \\
\text { versi- } \\
\text { veis }\end{array}$} & \multirow{2}{*}{$\begin{array}{l}\text { Tota } \\
\text { Gera }\end{array}$} \\
\hline & $\begin{array}{r}\text { Estados } \\
\text { Unidos }\end{array}$ & $\begin{array}{l}\text { Outros } \\
\text { Paises }\end{array}$ & $\begin{array}{r}\text { Org. } \\
\text { Intern. }\end{array}$ & Total & & \\
\hline $\begin{array}{l}\text { I - MERCADORIAS } \\
\text { (FOB) }\end{array}$ & 153 & -83 & - & 70 & 100 & 170 \\
\hline a) Exportações & 518 & 497 & - & 1.015 & 355 & 1.370 \\
\hline b) Importações & 365 & 580 & - & 945 & 255 & 1.200 \\
\hline $\begin{array}{l}\text { II - SERVIÇOS } \\
\text { III - MERCADORIAS } \\
\text { E SERVIÇOS }\end{array}$ & -201 & -136 & - & -342 & 8 & -350 \\
\hline$(I+I I)$ & -48 & -219 & - & -342 & 92 & -180 \\
\hline $\begin{array}{l}\text { IV - CAPITAIS } \\
\text { AUTONOMOS }\end{array}$ & -260 & 4 & - 86 & -342 & 5 & -347 \\
\hline a) Ingressos... & 250 & 155 & - & 405 & 5 & 410 \\
\hline b) Saidas ... & 510 & 151 & 86 & 747 & 10 & 757 \\
\hline $\begin{array}{l}\text { SUPERAVIT (+) OU } \\
\text { DEFICIT } \\
(-) \text { Liquido ...... }\end{array}$ & & & & & & \\
\hline $\mathrm{III}+\mathrm{IV} \ldots \ldots \ldots$ & -308 & -215 & -86 & -684 & 87 & -527 \\
\hline
\end{tabular}

É bem verdade que o nosso Balanço de Pagamentos, em 1963, obteve melhor resultado do que fôra previsto, encerrandose com um deficit de apenas US\$ 244 milhões. Isso em boa parte deveu-se à missão San Thiago Dantas que, como tantas vêzes vinha acontecendo em outras negociações, partira para os Estados Unidos da América em busca de reescalonamento de dívidas e obtenção de nossos créditos. Dentro dessas cediças limitações, pode-se dizer que a Missão teve êxito: compromissou financiamento de US\$ 200 milhões da AID; obteve desbloqueamento de créditos já antes negociados, no valor de US\$ 84 milhões, e um nôvo PL-480 para importação financiada, em 1963, de um milhão de toneladas de trigo, representando um desafogo de US\$ 56 milhões.

Para o biênio $1964 / 65$, as projeções da SUMOC previam Descobertos de US\$ 195 e US\$ 49 milhões. 


\section{QUADRO}

PROJEÇõES DO BALANÇO DE PAGAMENTOS PARA 1964/65

(em milhões de dólares)

\begin{tabular}{|c|c|c|c|}
\hline ITENS & 1964 & \multicolumn{2}{|c|}{1965} \\
\hline I - Transações Correntes & $-\quad 183$ & - & 159 \\
\hline a) Mercadorias & 237 & & 261 \\
\hline 1) Exportações (FOB) & 1.457 & & 1.511 \\
\hline 2) Importações (FOB) & -1.220 & - & 1.250 \\
\hline b) Serviços & - 420 & - & 420 \\
\hline II - Capitais autônomos e compensatórios & - 12 & - & $\begin{array}{l}110 \\
465\end{array}$ \\
\hline 1) Entradas & 453 & & \\
\hline $\begin{array}{r}\text { 2) Saídas } \\
\text { III _ } ~\end{array}$ & 465 & & 355 \\
\hline III - DESCOBERTO & 195 & - & 49 \\
\hline
\end{tabular}

Este passo, porém, já marca a performance da Revolução de 31 de Março, que transformou os deficits previstos para 1964 e 1965 em superavits de US\$ 4 e US\$ 331 milhões.

Mas para conseguir êsses superavits e afastar as pedras do caminho, a perversidade do Balanço de Pagamentos também Se pôs à mostra. Para equilibrá-lo, o Govêrno Castello Branco teve que enfrentar o cruel paradoxo de jogar com impulsos inflacionários, justamente para combater a inflação, do mesmo modo que teve de soltar a inflação reprimida de certos bens e serviços, visando ao aumento futuro da produção e da produtividade, e, conseqüentemente, o desaceleramento da inflação pelo processo gradualista.

Já hoje, saneado nosso Balanço de Pagamentos, o Brasil tem certamente presente o aspecto econômico e financeiro que êle encerra, de um lado como elemento dinâmico do desenvolvimento e de outro como fator inflacionário, quando do acúmulo excessivo de reservas líquidas. É claro, entretanto, que essas reservas assumem também um caráter político de suma importância, de vez que sem elas o País perde seu poder de barga- 
nha e de decisões nos foros internacionais. Há que dosá-las com engenho e arte.

A idéia da criação do Rio-Dólar, que começa a tomar vulto é um ponto de maior importância do que pode parecer à primeira vista. O Brasil desponta cada vez mais como líder nos países da América Latina. É justo, portanto, que comecemos a pensar também em criar moedas de reserva, ainda que num simples arremêdo dos paises ricos que podem desfrutar dessa vantagem. Considere-se que as divisas que para aqui acorrerem em depósitos nos bancos nacionais possam ter imediata opção para compra de O.R.T.N. ou Letras do Tesouro, de sorte que as autoridades monetárias disponham de reservas cambiais acumuladas, aqui mesmo, para comprar à vista máquinas e equipamentos no Exterior, com financiamentos, em cruzeiros, aos importadores nacionais. Da mesma forma, as agências do Banco do Brasil nos grandes centros financeiros internacionais devem ser induzidas, por delegação do Banco Central, ao pagamento à vista das importações, normalmente financiadas lá fora, utilizando-se êle próprio, o Banco do Brasil, de nossas reservas, a fim de que êsse pagamento à vista no Exterior resulte em financiamento interno, em cruzeiros, aos compradores nacionais. 0 lastro que a criação do Rio-Dólar pode oferecer nesse sentido assume aspecto que ouso qualificar de transcendental para inverter a posição desvantajosa dos fracos contra os fortes. A êstes, quando lhes devemos, somos devedores relapsos (caso de atrasados comerciais), mas êles, os países ricos, quando nos devem e giram com nossas reservas, que funcionam como financiamentos sem juros e a prazo indeterminado que the fazemos, apregoam que, para os países pobres, é motivo de orgulho nacional figurar como seus credores. Triste ironia.

Agora que o Brasil começa mais e mais a ser descoberto geològicamente, surge até mesmo a hipótese de criar-se, aqui, um mercado livre para o ouro. Poder-se-ia, até, cunhar moedaouro para venda no mercado interno, com lastro das reservas do Rio-Dólar, e assim obter cruzeiros, como medida desinflacionária, seja para financiar projetos que não carecem do recurso em moeda estrangeira, seja até mesmo para que essas moedas-ouro (de grande efeito psicológico para fortalecimento do cruzeiro-papel) funcionem como quase-dinheiro no open-market.

Enfim, o que se quer é que o nosso Balanço de Pagamentos seja o menos perverso possível.

Entretanto, pensando em têrmos mais altos (e que seria do mundo se não tivesse havido Cristo e se não existissem os 
poetas), há que lembrar as considerações do economista sueco Gunnar Adlerkalrsson, que recentemente abriu o ciclo de palestras internacionais promovido pela Faculdade Cândido Mendes. Ponderou o ilustre conferencista que a catástrofe de Malthus ainda não se concretizou, mas o problema continua existindo. $\mathrm{E}$, se durar mais de 400 anos, ter-se-á tanta gente no mundo que sobrará apenas um metro quadrado para cada habitante. Mas, sob êsse aspecto, ainda se pode filosofar com Lord Keynes (...) "In the long run we all will be dead".

O que mais impressiona, todavia, é o problema atual da distribuição de renda no mundo. Para cada 100 dólares gastos nos países pobres corresponde um consumo de 1.800 dólares nos países ricos. Dividindo-se o mundo em cinco grupos distintos, divulga-se que no primeiro, o mais pobre, há um consumo mínimo de $2,9 \%$ da totalidade dos recursos humanos; no grupo seguinte, êsse consumo é de $3,5 \%$; no grupo do meio é de $4,7 \%$; no grupo intermediário é de $10,2 \%$; e no mais rico (Estados Unidos, Suécia, Japão, Alemanha Ocidental e outros) atinge a $66,4 \%$.

E, se se juntam todos êsses dados, tem-se que $60 \%$ da população mundial consome apenas $11 \%$ da renda total, enquanto a população dos países ricos absorve $66,4 \%$.

Por tudo isso, ainda é oportuno, para terminar, ter presentes as palavras de Morgenthau na Conferência de Breton Woods, em julho de 1944, quando afirmou:

"Espero que a Conferência concentre sua atenção em dois princípios - a prosperidade não é uma substância finita que se reduza ao ser dividida; em conseqüência, a prosperidade é indivisivel. Mas a miséria é também contagiosa." 
